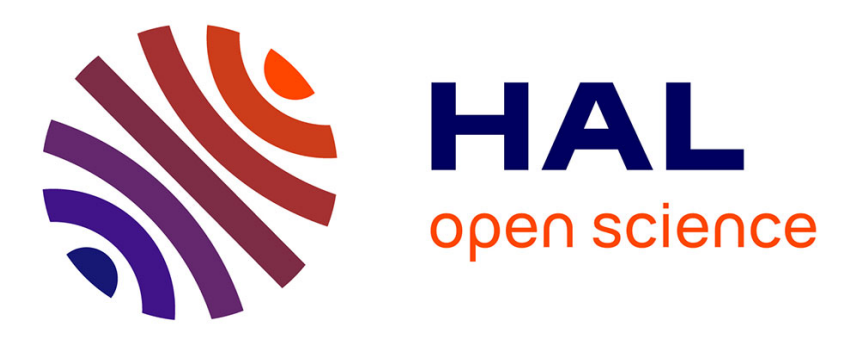

\title{
Technical efficiency and determinants of mobility patterns in European agriculture
}

Zoltan Bakucs, Imre Ferto, Laure Latruffe, Yann Desjeux

\section{To cite this version:}

Zoltan Bakucs, Imre Ferto, Laure Latruffe, Yann Desjeux. Technical efficiency and determinants of mobility patterns in European agriculture. 28. International Association of Agricultural Economists (IAAE) Triennial Conference, International Association of Agricultural Economists (IAAE). INT., Aug 2012, Foz de Iguaçu, Brazil. 10 p. hal-01208892

\section{HAL Id: hal-01208892 \\ https://hal.science/hal-01208892}

Submitted on 3 Jun 2020

HAL is a multi-disciplinary open access archive for the deposit and dissemination of scientific research documents, whether they are published or not. The documents may come from teaching and research institutions in France or abroad, or from public or private research centers.
L'archive ouverte pluridisciplinaire HAL, est destinée au dépôt et à la diffusion de documents scientifiques de niveau recherche, publiés ou non, émanant des établissements d'enseignement et de recherche français ou étrangers, des laboratoires publics ou privés. 


\title{
Technical efficiency and determinants of mobility patterns in European agriculture
}

\begin{abstract}
A comparative analysis of farm technical efficiency in $8 \mathrm{EU}$ member states, focusing on the relative performance fluctuation over time, i.e. whether poorly performing farms remain always inefficient whilst some farms are always efficient is presented in this paper. Results show that on average $60 \%$ of farms maintain their efficiency ranking in two consecutive years, whilst $20 \%$ improve and $20 \%$ worsen their positions. Due to the unstable economic conditions, farms in NMS are more mobile than those in EU15. Second stage regression of mobility scores upon a set of farm specific explanatory variables offers some explanations of the mobility patterns.
\end{abstract}

KEYWORDS: Farm technical efficiency, SFA, FADN, stability analysis

JEL CLASSIFICATION: P52, Q12

\section{INTRODUCTION}

The technical efficiency refers to the situation where it is impossible for a farm to produce more with given technology. There are two possibilities for farmers. First, produce larger output using the same inputs, second, produce the same output with less amounts of inputs. In practice, the research and policy interests are focusing on the relative position in terms of efficiency of particular farm with respect to others. Consequently, the technical efficiency can be described by the relationship between observed output and some ideal or potential production. There is wealth of methodological and empirical literature focusing on the issues in efficiency and productivity (standard theoretical references Coelli et al., 2005; Kumbhakar and Lovell, 2000; while comprehensive overview on empirical research Bravo-Ureta et al. 2007). There exist two main approaches developed over time for analysing technical efficiency in agriculture. (1) The construction of a nonparametric piecewise linear frontier using linear programming method known as data envelopment analysis (DEA); (2) the estimation of a parametric production function using stochastic frontier analysis (SFA). We apply stochastic frontier analysis to measure efficiency. In addition, most studies focus on a single country's agricultural sector, thus the comparative analysis of the technical efficiency is rather scarce (see recent exceptions Barnes et al 2010, and Zhou and Lansink 2010). More importantly, easier availability for research of farm level data, namely FADN data in the EU may provide interesting insights for policy makers on farm level technical efficiency in order to develop more targeted policy, thus improving efficiency in European agriculture. 
The aim of this paper is to analyse the stability and mobility patterns od technical efficiency scores for some EU countries including Belgium, Estonia, France, Germany, Hungary, Italy, The Netherlands and Sweden. The availability of long period datasets between 1990 and 2006, allow us to concentrate on the long time trends in technical efficiency especially in the EU15 member states. This study is the first which may provide a comprehensive overview on the development in farm level efficiency across eight European countries.

The rest of this paper is organised as follows. Section 2 presents a brief review on the methodology including stochastic frontier analysis and stability approaches. Section 3 describes the datasets and provides some descriptive statistics on agricultural structures. Section 4 presents the main results of the analysis in two steps. First we outline the results based on the SFA approach. Second, we present stability analysis, and determinants of farm mobility with respect to their position in the distribution of technical efficiency scores. Finally the last chapter summarizes main results of the paper and concludes.

\section{MeTHodology}

\subsection{Stochastic Frontier Analysis}

Within the parametric approaches, the Stochastic Frontier Analysis, (SFA) is commonly used. Aigner at al. (1977) and Meeusen and Van den Broeck (1977) have simultaneously yet independently developed the use of SFA in efficiency analysis.

The main idea is to decompose the error term of the production function into two components, one pure random term $\left(v_{i}\right)$ accounting for measurement errors and effects that cannot be influenced by the firm such as weather, trade issues, access to materials, and a non-negative one, measuring the technical inefficiency, i.e. the systematic departures from the frontier $\left(u_{i}\right)$ :

$$
\begin{gathered}
Y_{i}=f\left(x_{i}\right) \exp \left(v_{i}-u_{i}\right) \quad \text { or, equivalently: } \\
\left.\ln (Y)_{i}=\beta x_{i}+v_{i}-u_{i}\right)
\end{gathered}
$$

where $\mathrm{Y}_{i}$ is the output of the $i^{\text {th }}$ firm, $x_{i}$ a $(\mathrm{k}+1)$ vector of inputs used in the production, $f(\cdot)$ the production function, $u_{i}$ and $v_{i}$ the error terms explained above, and finally, $\beta$ a $(\mathrm{k}+1)$ column vector of parameters to be estimated. The output orientated technical efficiency, (TE) is actually the ratio between the observed output of firm $i$ to the frontier, i.e. the maximum possible output using the same input mix $x_{i}$.

Arithmetically, technical efficiency is equivalent with:

$$
T E_{i}=\frac{Y_{i}}{Y_{i}^{*}}=\frac{\exp \left(x_{i} \beta+v_{i}-u_{i}\right)}{\exp \left(x_{i} \beta+v_{i}\right)}=\exp \left(-u_{i}\right), 0 \leq T E_{i} \leq 1 \text {. }
$$

Contrary to the non-parametric DEA approach, where all technical efficiency scores are located on, or below the efficient frontier (see below), in SFA they are allowed to be above the frontier, if the random error $v$ is larger than the non-negative $u$.

Applying SFA methods requires distributional and functional form assumptions. First, because only the $w_{i}=v_{i}-u_{i}$ error term can be observed, one needs to have specific assumptions about the distribution of the composing error terms. The random term $v_{i}$, is usually assumed to be identically and independently distributed drawn from the normal distribution, $N\left(0, \sigma_{v}^{2}\right)$, independent of $u_{\mathrm{i}}$. There are a number of possible assumptions regarding the distribution of the non-negative error term $u_{i}$ associated with technical inefficiency. However most often it is 
considered to be identically distributed as a half normal random variable, $N^{+}\left(0, \sigma_{u}^{2}\right)$ or a normal variable truncated from below zero, $N^{+}\left(\mu, \sigma_{u}^{2}\right)$.

Second, being a parametric approach, we need to specify the underlying functional form of the Data Generating Process, DGP. There are a number of possible functional form specifications available, however most studies employ either Cobb-Douglas (CD):

$f\left(x_{i}\right)=e^{\beta_{0}} \prod_{k=1}^{K} x_{i k}^{\beta_{k}}$

or TRANSLOG (TL) specification:

$\ln f\left(x_{i}\right)=\sum_{k=1}^{K} \beta_{k} \ln x_{i k}+\frac{1}{2} \sum_{k=1}^{K} \sum_{j=1}^{K} \beta_{k j} \ln x_{i k} \ln x_{j k}$.

Because the two models are nested, it is possible to test the correct functional form by a Likelihood Ratio, LR test. The TL is a more flexible functional form, whilst the CD restricts the elasticities of substitution to 1 . The model could be estimated either with Corrected Ordinary Least Squares, COLS or Maximum Likelihood, ML. With the availability of computer software, the estimation by ML became less computationally demanding, and the ML estimator was found to be significantly better than COLS (Coelli et al.,1997).

With panel data, TE can be chosen to be time invariant, or to vary systematically with time. To incorporate time effects, Battese and Coelli (1992) define the non-negative error term as exponential function of time:

$u_{i t}=\exp \left[(-\eta(t-T)] u_{i}\right.$

where $t$ is the actual period, $T$ the final period, and $\eta$ a parameter to be estimated. TE either increases $(\eta>0)$, decreases $(\eta<0)$ or it is constant over time, i.e. invariant $(\eta=0)$. LR tests can be applied to test the inclusion of time in the model. Since TE is allowed to vary, the question arise what determines the changes of TE scores. Early studies applied a two-stage estimation procedure, first determining the inefficiency scores, and then, in a second stage regressing TE scores upon a number of firm specific variables assumed to explain changes in inefficiency scores. Some authors however showed that conflicting assumptions are needed for the two different estimation stages. In the first stage, the error term representing inefficiency effects, are assumed to be independently and identically distributed, whilst in the second stage they are assumed to be function of firm specific variables explaining inefficiency, i.e. they are not independently distributed (Curtiss, 2002). Battese and Coelli (1995) proposed a one stage procedure where firm specific variables are used to explain the predicted inefficiencies within the SFA model. The explanatory variables are related to the firm specific mean $\mu$ of the nonnegative error term $u_{i}$ :

$\mu_{i}=\sum_{j} \delta_{j} z_{i j}$

where $\mu_{i}$ is the $i^{\text {th }}$ firm-specific mean of the non-negative error term; $\delta_{j}$ are parameters to be estimated; $z_{i j}$ are $i^{\text {th }}$ firm-specific explanatory variables.

Using cross-section or panel data may often lead to heteroscedasticity in the residuals. With heteroscedastic residuals, OLS estimates remain unbiased but no longer efficient. In frontier models however, the consequences of heteroscedasticity are much more severe, as the frontier changes when the dispersion increases. Caudill et al. (1995) introduced a model which incorporates heteroscedasticity into the estimation. That is done by modelling the relationship between the variables responsible for heteroscedasticity and the distribution parameter $\sigma_{u}$ :

$\sigma_{u i}=\exp \left(\sum_{j} x_{i j} \rho_{j}\right)$ 
where $x_{i j}$ are the $j^{\text {th }}$ input of the $i^{\text {th }}$ farm, assumed to be responsible for heteroscedasticity, and $\rho_{j}$ a parameter to be estimated.

Within SFA approach it is possible to test whether any form of stochastic frontier production function is required or the OLS estimation is appropriate using a LR test. Using the parameterisation of Battese and Cora (1977), define $\gamma$, the share of deviation from the frontier that is due to inefficiency:

$\gamma=\frac{\sigma_{u}^{2}}{\sigma_{v}^{2}+\sigma_{u}^{2}}$

where $\sigma_{v}^{2}$ is the variance of the $v$ and $\sigma_{u}^{2}$ the variance of the $u$ error term.

It should be noted however, that the test statistic has a 'mixed' chi square distribution, with critical values tabulated in Kodde and Palm (1996).

\subsection{Stability Analysis}

Efficiency scores as such, do not reveal much about the fluctuation of farms' relative performance. From policy point of view however, it is an interesting question whether low performing farms are always inefficient and vice versa, i.e. farms with higher TE scores are efficient throughout the period. Policy relevance is given by the fact that chronically lower performing farms may be targeted with specific measures in order to improve their efficiency scores. With large panel datasets however, due to sample attrition it is not feasible to follow the TE scores of given farms through longer time periods, therefore comparisons between consecutive years were done. We follow the stability analysis methodology outlined by Barnes et al. (2010). Yearly farm TE scores were classified by terciles, then transition matrices linking two consecutive years were constructed, that indicate whether the considered farm remained in the same tercile, or its relative position has worsened, or contrary, improved.

The degree of mobility in patterns of SFA scores can be summarised using indices of mobility. These formally evaluate the degree of mobility throughout the entire distribution of SFA scores and facilitate direct cross-country comparisons. The first of these indices $\left(\mathrm{M}_{1}\right.$, following Shorrocks, 1978) evaluates the trace (tr) of the transition probability matrix. This index thus directly captures the relative magnitude of diagonal and off-diagonal terms, and can be shown to equal the inverse of the harmonic mean of the expected duration of remaining in a given cell.

$$
M_{1}=\frac{K-\operatorname{tr}(P)}{K-1}
$$

where $\mathrm{K}$ is the number of cells, and $\mathrm{P}$ is the transition probability matrix.

The second index $\left(\mathrm{M}_{2}\right.$, after Shorrocks, 1978 and Geweke et al., 1986) evaluates the determinant (det) of the transition probability matrix.

$\mathrm{M}_{2}=1-|\operatorname{det}(\mathrm{P})|$ 
In both indices, a higher value indicates greater mobility, with a value of zero indicating perfect immobility. The mobility indices as such, can only serve as to rank analysed countries field crop sectors according to their mobility. In order to answer the question of why certain countries technical efficiency scores are more mobile, a second stage regression is performed, regressing mobility scores on a set of explanatory variables. This analysis is however is only performed for the EU15 countries represented in this paper, due to the shortness of NMS's available dataset.

\section{DATA}

We use the EU FADN data. Due to their relative importance and large number of available observations compared to other sectors, field crop farms (TF1) are considered in this paper. Data source is the FADN database from 1990 to the latest available year (2006) in case of EU15 and 2004-2006 for NM. Inconsistent data and outliers were removed from the initial datasets.

Table 1. Descriptive statistics and concentration index of field crop farms (UAA)

\begin{tabular}{|l|l|l|l|l|}
\hline & $\begin{array}{l}\text { Field } \\
\text { Crop }\end{array}$ & \multicolumn{2}{c|}{ Utilised Agricultural Area } \\
\hline & \multicolumn{2}{|c|}{ start period } & \multicolumn{2}{c|}{ end period } \\
\hline & mean & Gini coefficient & mean & Gini coefficient \\
\hline Belgium & 54.00 & 0.2975 & 73.87 & 0.3159 \\
\hline Estonia & 230.11 & 0.4754 & 240.27 & 0.4824 \\
\hline France & 80.89 & 0.3436 & 135.88 & 0.3323 \\
\hline Germany & 47.11 & 0.3501 & 252.02 & 0.6358 \\
\hline Hungary & 255.45 & 0.6671 & 240.05 & 0.6360 \\
\hline Italy & 19.61 & 0.5081 & 50.96 & 0.6503 \\
\hline Netherlands & 62.34 & 0.3220 & 82.81 & 0.3684 \\
\hline Sweden & 83.61 & 0.2939 & 120.19 & 0.4515 \\
\hline
\end{tabular}

Source: authors' calculations

Tables 1 shows that an obvious concentration process happened in all analysed countries during the period. With the exception of Hungary, sample means of farm size for all countries do increase. In some countries, average sample mean increased dramatically (e.g. field crop farm size in Germany ${ }^{1}$ increased fivefold, Italian field crop farm sizes trebled, Swedish, French field crop farm sizes doubled). The second column for both the starting and end period presents the Gini concentration index. Generally the concentration index also increases between the start and end periods, but by far not as dramatically as farm size means. The highest sample size means and concentration indices are reported for the NMS, Hungary and Estonia. With the exception of these two countries however, interestingly, a higher sample size mean does not translate into a higher concentration index.

\footnotetext{
${ }^{1}$ This is mostly due to the effects of the German reunification process, by the inclusion of the large scale former GDR state owned agricultural holdings in the sample.
} 


\section{RESULTS}

\subsection{Development of farm efficiency}

Technical efficiency (TE) estimates obtained with SFA are reported on figure 1. Results are plausible, when mean technical efficiency scores are computed they are largely in line with results obtained by previous studies.

Figure 1. Technical efficiency scores for field crop farms

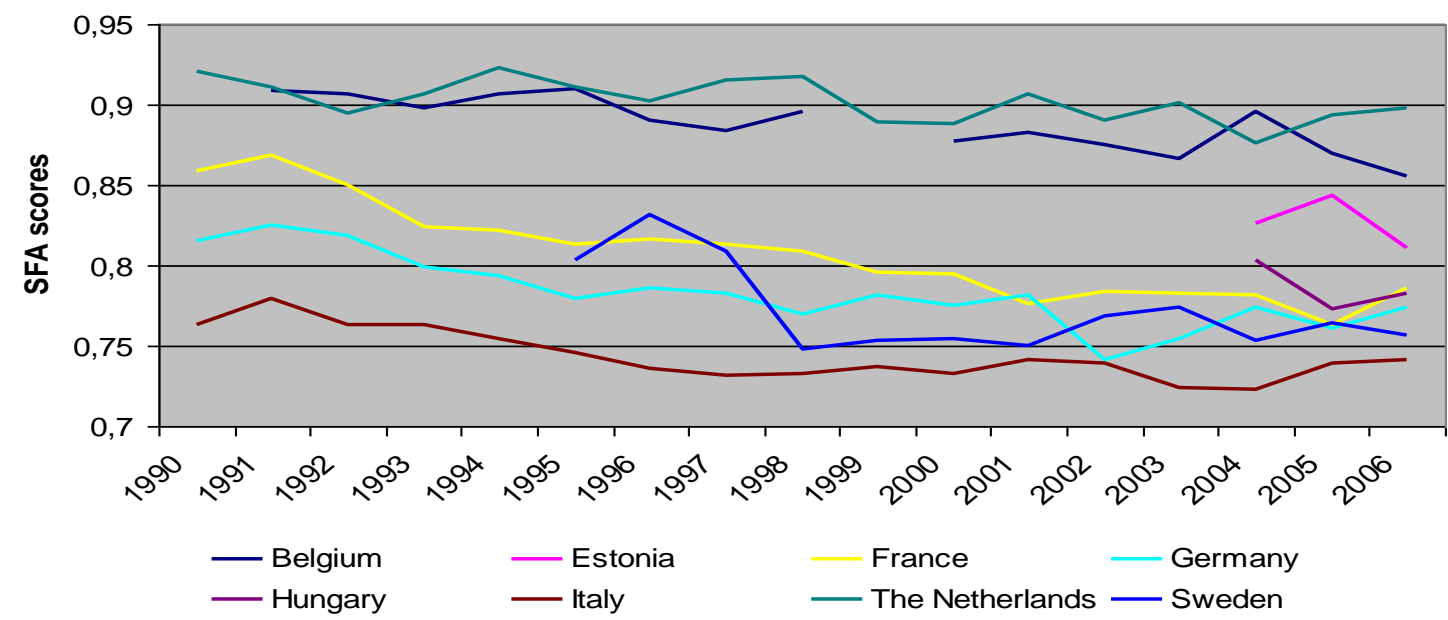

Some examples found in the literature confirm this. Zhu and Oude Lansink (2010) employ the longest time-span in their research, and focus on several of the countries represented in this paper, thus may be used as a benchmark to assess our results. The simple visual inspection of the efficiency estimates figures is difficult to determine whether on long run average per country efficiency scores increase or decrease. We have therefore analysed this issue econometrically by regressing the TE scores for each country (for all years pooled together) on a single explanatory variable: the time trend. Table 2 presents the estimates, and their significance levels.

Table 2. OLS regression of efficiency scores on a time trend

\begin{tabular}{|l|l|}
\hline & Field Crop \\
\hline Belgium & $-0.003^{* * *}$ \\
\hline France & $-0.007^{* * *}$ \\
\hline Germany & $-0.005^{* * *}$ \\
\hline Italy & $-0.003^{* * *}$ \\
\hline Netherlands & $-0.002^{* * *}$ \\
\hline Sweden & $-0.005^{* *}$ \\
\hline
\end{tabular}

Note: $* * *, * *, *$ significant on 1,5 and $10 \%$ respectively.

Source: authors' calculations

Coefficients are significant, small and negative across regressions, suggesting a decreasing average technical efficiency score for each country. The regressions were not performed for NMS since their sample covers only 3 years. 


\subsection{Stability Analysis}

Following the technique outlined in the methodology section, we performed the stability analysis for Belgium, Estonia, France, Germany, Hungary, Italy, The Netherlands and Sweden respectively. Our findings suggest a surprising stability of results across countries over time. Table 3 presents the mean values of the percentage of farms in consecutive years that remain in the same tercile, along those increasing or decreasing their respective terciles.

Table 3. Stability analysis results: percentage of farms in the same tercile during two consecutive years

\begin{tabular}{|l|c|c|c|}
\hline & \multicolumn{3}{|c|}{ Field Crop } \\
\hline & increase & remain & decrease \\
\hline Belgium & 0.20 & 0.61 & 0.19 \\
\hline Estonia & 0.26 & 0.46 & 0.28 \\
\hline France & 0.19 & 0.61 & 0.20 \\
\hline Germany & 0.20 & 0.61 & 0.19 \\
\hline Hungary & 0.26 & 0.48 & 0.26 \\
\hline Italy & 0.20 & 0.59 & 0.21 \\
\hline Netherlands & 0.20 & 0.58 & 0.21 \\
\hline Sweden & 0.18 & 0.65 & 0.17 \\
\hline Source: auth
\end{tabular}

Source: authors' calculations

As suggested earlier, results are surprisingly stable: about $60 \%$ of all farms remain in the same tercile two consecutive years, whilst about $15-20 \%$ of farms decrease and increase their performance moving down or up a tercile. Results obtained here, are completely in line with those of Barnes et al. (2010) for crop farming in England, Scotland, Wales and Northern Ireland. On average, $15 \%$ (Estonia) to $24 \%$ (Germany) of field crop farms remained in the top tercile each year, $13 \%$ (Estonia and Hungary) to $17 \%$ (Belgium, Germany) in the middle tercile and $17 \%$ (Estonia, Hungary) to 22\% (France) in the lower tercile (table 4).

Table 4. Average change in technical efficiencies for field crop farms depending on their tercile movement

\begin{tabular}{|l|l|l|l|l|l|l|l|l|}
\hline & Belgium & Estonia & France & Germany & Hungary & Italy & Netherlands & Sweden \\
\hline \multicolumn{8}{|c|}{ Farms remaining each year } \\
\hline tercile 1 & 0.224 & 0.150 & 0.222 & 0.243 & 0.173 & 0.211 & 0.226 & 0.226 \\
\hline tercile 2 & 0.174 & 0.133 & 0.164 & 0.169 & 0.134 & 0.160 & 0.155 & 0.181 \\
\hline tercile 3 & 0.208 & 0.173 & 0.222 & 0.202 & 0.171 & 0.215 & 0.201 & 0.240 \\
\hline \multicolumn{8}{|c|}{ Farms increasing each year } \\
\hline tercile 2-1 & 0.081 & 0.093 & 0.082 & 0.083 & 0.100 & 0.089 & 0.084 & 0.078 \\
\hline tercile 3-1 & 0.030 & 0.058 & 0.022 & 0.025 & 0.057 & 0.031 & 0.026 & 0.017 \\
\hline tercile 3-2 & 0.091 & 0.115 & 0.089 & 0.084 & 0.103 & 0.083 & 0.094 & 0.083 \\
\hline \multicolumn{8}{|c|}{ Farms decreasing each year } \\
\hline tercile 1-2 & 0.076 & 0.102 & 0.086 & 0.088 & 0.103 & 0.091 & 0.087 & 0.082 \\
\hline tercile 1-3 & 0.035 & 0.053 & 0.023 & 0.022 & 0.060 & 0.031 & 0.030 & 0.013 \\
\hline tercile 2-3 & 0.082 & 0.124 & 0.089 & 0.084 & 0.099 & 0.089 & 0.097 & 0.081 \\
\hline
\end{tabular}

Source: authors' calculations

It is probably more interesting the percentage of farms that changed their terciles over the year. An average of $10 \%$ (France, Germany) to $15 \%$ (Estonia, Hungary) improved their 
performance by shifting into a higher ( 2 to 1 or 3 to 1 ) tercile, whilst almost the same, on average 10\% (France) to 16\% (Hungary) fell from the top or middle tercile to the lowest. It is interesting to note, that New Member States (Estonia and Hungary) register the highest average percentage of farms either dramatically increasing or decreasing their terciles, suggesting a highly unstable yearly performance. These countries also register the lowest percentages of farms that are stable in the same tercile during the year.

The mean of yearly mobility indexes, M1 and M2 (see equations 9 and 10 are presented in table 5 . For both indices a higher value indicates greater mobility, whilst a value close to zero indicates perfect immobility.

Table 5. Means of M1 and M2 mobility indices for field crop farms

\begin{tabular}{|l|c|c|}
\hline & \multicolumn{2}{|c|}{ Field Crop } \\
\hline Belgium & M1 & M2 \\
\hline Estonia & 0.59 & 0.82 \\
\hline France & 0.81 & 0.99 \\
\hline Germany & 0.59 & 0.86 \\
\hline Hungary & 0.58 & 0.85 \\
\hline Italy & 0.78 & 0.97 \\
\hline Netherlands & 0.62 & 0.88 \\
\hline Sweden & 0.63 & 0.86 \\
\hline Source: & 0.52 & 0.81 \\
\hline
\end{tabular}

Source: authors' calculations

Index means are remarkably similar across countries in this research. It is important to notice, that the M2 index ranks countries in the same way as M1 does, implying consistency of results. M1 ranges from 0.52 to 0.63 whilst M2 from 0.81 to 0.88 , indicating a similar degree of mobility. M1 and M2 indices are significantly higher for New Member States (Estonia and Hungary). M2 reaches 0.97 and 0.99 in Hungary and Estonia, suggesting higher mobility of SFA scores throughout the entire distribution. The lowest mobility scores are recorded for Sweden.

\subsection{Some determinants of farm mobility}

An obvious research question is whether one can identify some factors influencing the mobility indices. An obvious set of explanatory variables would be the farm structure and organisational form (e.g. family, corporate or cooperative farms) however these data is only available in national FADN databases. Instead, in this paper we use input ratio variables, available in EU FADN database. A number of explanatory variables were regressed using different specifications (e.g. nominal, log-log, etc.) here we present the panel regression output with the most significant results. Since M1 and M2 indices are qualitatively similar, but regressing M2 yields more significant results, we focus on M2 only. Table 6 presents the panel regression results of the mobility index upon farm size (measured in UAA), land per labour and capital (measured in total assets) per labour input ratios, normalised by their mean.

Table 6. Panel regression of M2 mobility index upon input ratios

\begin{tabular}{|l|l|}
\hline Variables & coefficient \\
\hline Farm size & 0.000 \\
\hline Land/labour & $-0.056^{* * *}$ \\
\hline Capital/labour & $-0.025^{* * *}$ \\
\hline constant & $0.927 * * *$ \\
\hline \multicolumn{2}{|l|}{ Note: own calculations, ${ }^{* * *}$ significant at $1 \%$}
\end{tabular}


Except farm size, all explanatory variables and the constant are highly significant. The sign of the coefficients rather than the magnitude is important for the analysis. Regression results emphasise, that the higher the land per labour and capital per labour farm input ratios, the less likely is that corresponding technical efficiency score changes the position within the distribution during two consecutive years. Further research could include farm organisation and managerial attribute variables amongst explanatory variables to better capture the endogenous determinants of technical efficiency scores changing their relative positions in time.

\section{CONCLuSions}

The aim of this paper is to present and analyse the stability over time, and the determinants of mobility of the field crop farm technical efficiency indicator for Belgium, Estonia, France, Germany, Hungary, Italy, The Netherlands and Sweden. The availability of long period datasets between 1990 and 2006, allows us to concentrate on the long time trends in technical efficiency. This study is the first which may provide a comprehensive overview on the development in farm level efficiency across eight European countries.

Our main results are following. Generally, all countries have relatively high levels of mean efficiency ranging from 0.72 to 0.92 . A slightly decreasing trend of efficiency may be observed for all countries. Technical Efficiency estimates are largely in line with those obtained by previous studies.

We investigate the issue of how relative performance of farms fluctuates in terms of technical efficiency over time. We may hypothesise that many poorly performing farms remain inefficient over time and some farmers are performing always very efficiently. We can identify farms which are usually at the bottom or top of the efficiency ranking. However, the FADN data has an inherent problem for long time period analysis arising from its rotated panel nature, namely that not all the farms are observed for the whole period. Thus we needed to calculate transition matrices in each consecutive year. Surprisingly stability analysis revealed that in average $60 \%$ of farms maintain their efficiency ranking in two consecutive years, whilst $20 \%$ improve and $20 \%$ worsen their positions for all countries. However, these ratios slightly fluctuate around these values for one year to next year. Mobility analysis ranks countries according to the mobility of SFA scores within the distribution. Farms in New Member States are more mobile than those in EU15. This may be due to the unstable economic conditions of farms in these countries, where e.g. inputs access is not always secured or is costly. Finally, some insight into the possible determinants of farm technical efficiency mobility is offered, emphasising the importance of the input mix ratio used.

\section{REFERENCES}

Aigner, D., Lovell, C. and Schmidt, P. (1977) Formulation and estimation of stochastic production function models, Journal of Econometrics, 6, 21-37.

Barnes, A.P., Revoredo-Giha, C., Sauer, J. Elliott, J. and Jones, G. (2010). A report on technical efficiency at the farm level 1989 to 2008. Report for Defra, London.

Battese, G.E. and Coelli, T.J., (1992). Frontier production functions, technical efficiency and panel data: with application to paddy farmers in India. Journal of productivity analysis, 3 (1), 153-169.

Battese, G. and T. Coelli (1995). "A model for technical inefficiency effects in a stochastic frontier production function for panel data", Empirical Economics 20: 325-332. 
Battese, G. and Corra, G., (1977). Estimation of a production frontier model with the application of the pastoral zone of Eastern Australia. Australian journal of agricultural economics, 21 (3), 167-179.

Bravo-Ureta, B.E., Solís, D., López, C.V.H.M., Maripani, J.F., Thiam, A., and Rivas, T. (2007). Technical efficiency in farming: a meta-regression analysis. Journal of Productivity Analysis, 27, 57-72

Brümmer, B., Glauben, T., Thijssen, G. (2002). Decomposition of productivity growth using distance functions: The case of dairy farm sin three European countries. American Journal of Agricultural Economics 84(3), 628-644.

Caudill, B.S., Ford, J.M. and Gropper, D.M., (1995). Frontier estimation and firm-specific inefficiency measures in the presence of heteroscedasticity. Journal of business and economic statistics, 13 (1), 105-111.

Coelli, T.J., D.S. P. Rao, C.J. O’Donnell and G.E. Battese (2005). “An introduction to Efficiency and productivity analysis." Springer, USA

Coelli, T., Perelman, S., Van Lierde (2006). CAP Reforms and Total Factor Productivity Growth in Belgian Agriculture: A Malmquist Index Approach. Contributed paper for presentation at the 26th Conference of the International Association of Agricultural Economists (IAAE) held on August 12-18 at the Gold Coast, Australia.

Curtiss, J., 2002. Efficiency and structural changes in transition: a stochastic frontier analysis of Czech crop production. Institutional Change in Agriculture and Natural Resources Vol. 12. The Netherlands: Shaker Verlag.

Geweke, J., Marshall, R., and Zarkin, G. (1986). Mobility indices in continuous time Markov chains. Econometrica 54 (6): 1407-1423.

Hansson, H. (2007). The links between management's critical success factors and farm level economic performance on dairy farms in Sweden. Food Economics, Acta Agricult Scand C, 2007; 4: 77-88.

Kodde, D.A. and Palm, F.C. (1986). Wald criteria for jointly testing equality and inequality restrictions. Econometrica, 54 (5) 1243-1248.

Kumbhakar, S. C. and C. Lovell (2000), Stochastic Frontier Analysis, Cambridge University Press, Cambridge

Kleinhanß, W., Murillo, C., San Juan, C., Sperlich, S. (2007). Efficiency, subsidies, and environmental adaptation of animal farming under CAP. Agricultural Economics 36 49-65.

Larsen, K. (2010). Effects of machinery-sharing arrangements on farm efficiency: evidence from Sweden. Agricultural Economics 41 (2010) 497-506.

Meeusen, W. and van den Broeck, J. (1977) Efficiency estimation from Cobb-Douglas production functions with composed error, International Economic Review, 18, 435-44.

Shorrocks, A. (1978). The measurement of mobility. Econometrica, 46 (5): 1013-1024.

Vasiliev, N., Astover, A., Mõtte, M., Matveev, E., Noormets, M., Endla Reintam, E., Hugo

Roostalu, H. (2008). Efficiency of Estonian grain farms in 2000-2004. Agricultural and Food Science, 17., 31-40.

Zhu., X. and Oude Lansink, A. (2010). Impact of CAP Subsidies on Technical Efficiency of Crop Farms in Germany, the Netherlands and Sweden. Journal of Agricultural Economics, 61, (3): 545-564 